\title{
Evaluation of an alkali-polymer flooding technique for enhanced oil recovery in Trinidad and Tobago
}

\author{
Kyle Medica ${ }^{1} \cdot$ Rean Maharaj ${ }^{1}$. David Alexander ${ }^{1} \cdot$ Mohammad Soroush $^{1}$
}

Received: 21 May 2020 / Accepted: 8 August 2020 / Published online: 24 August 2020

(c) The Author(s) 2020

\begin{abstract}
Trinidad and Tobago (TT) is seeking to develop more economical methods of enhanced oil recovery to arrest the decline in crude oil production and to meet the current and future energy demand. The utilization of alkaline-polymer flooding to enhance oil recovery in TT requires key studies to be conducted to obtain critical information of the flooding system (soil type, additive type, $\mathrm{pH}$, adsorption characteristics and rheological (flow) characteristics). Understanding the role of, interplay and optimizing of these variables will provide key input data for the required simulations to produce near realistic projections of the required EOR efficiencies. The parameters of various wells in TT were compared to the screening criteria for alkali-polymer flooding, and the EOR 4 well was found to be suitable and thus selected for evaluation. Laboratory adsorption studies showed that the $1000 \mathrm{ppm}$ xanthan gum flooding solution containing $0.25 \% \mathrm{NaOH}$ exhibited the lowest absorption capacity for the gravel packed sand and exhibited the lowest viscosity at all the tested shear rates. The lowest adsorption was $2.27 \times 10^{-7} \mathrm{lbmole} / \mathrm{ft}^{3}$ which occurred with the $1000 \mathrm{ppm}$ xanthan gum polymer containing $0.25 \% \mathrm{NaOH}$, and the evidence showed that the polymer was adsorbed on the other side of the faults, indicating that it has moved further and closer to the producing well. Implementation of an alkali polymer flooding resulted in an incremental increase in the recovery factors $(\sim 3 \%)$ compared to polymer flooding; however, a change in the oil recovery as a function of the alkaline concentration was not observed. The simulated economic analysis clearly shows that all the analysed EOR scenarios resulted in economically feasible outcomes of net present value (NPV), Internal Rate of Return (IRR) and payback period for oil price variations between $\$ 35$ and $\$ 60$ USD per barrel of oil. A comparison of the individual strategies shows that the alkali-polymer flood system utilizing $0.25 \%$ sodium hydroxide with $1000 \mathrm{ppm}$ xanthan gum is the best option in terms of cumulative production, recovery factor, NPV, IRR and time to payback.
\end{abstract}

Keywords Alkali-polymer flood $\cdot$ Xanthan gum $\cdot$ Aquagel $\cdot$ EOR $\cdot$ Waterflood

\section{Introduction}

The economy of Trinidad and Tobago (TT) is heavily reliant on the energy sector, and the GDP of the twin island republic has seen a decline since 2014 mainly due to fluctuating oil and natural gas commodity prices as well as a constant decrease in crude oil production. With specific reference to crude oil production, and as shown in Fig. 1, Trinidad and Tobago averaged 107.19 MBBL/D from 1994 until 2019, reaching an all-time high of $156 \mathrm{MBBL} / \mathrm{D}$ in March 2005 and a record low of 51 MBBL/D in March 2019.

Rean Maharaj

rean.maharaj@utt.edu.tt

1 University of Trinidad and Tobago, UTT, Couva, Trinidad and Tobago
To mitigate the decline in crude oil production, more economical methods of enhanced recovery are constantly being sought and developed. TT has produced over $320 \mathrm{MMbbls}$ of oil utilizing various secondary and other EOR processes such as WASP, steamflood and waterflood (Ministry of Energy and Energy Industries 2019). In recent times, there has been a shift from simple waterflooding due to associated uneconomical high water cuts, inadequate water supply for injection, the occurrence of viscous fingering as well as mechanical and operational problems (Sinanan et al. 2016). Strategies involving the addition of polymeric additives to water are gaining attention as it has been shown to increase the viscosity of the mixture thus improving its sweep efficiency facilitating enhanced oil recovery. Researchers have found that polymer flood techniques have demonstrated desirable properties of mobility control and viscosity 
Fig. 1 Crude oil production data from Trinidad and Tobago by year from 1994 to 2019 (https ://tradingeconomics.com/trini dad-and-tobago/crude-oil-produ ction)

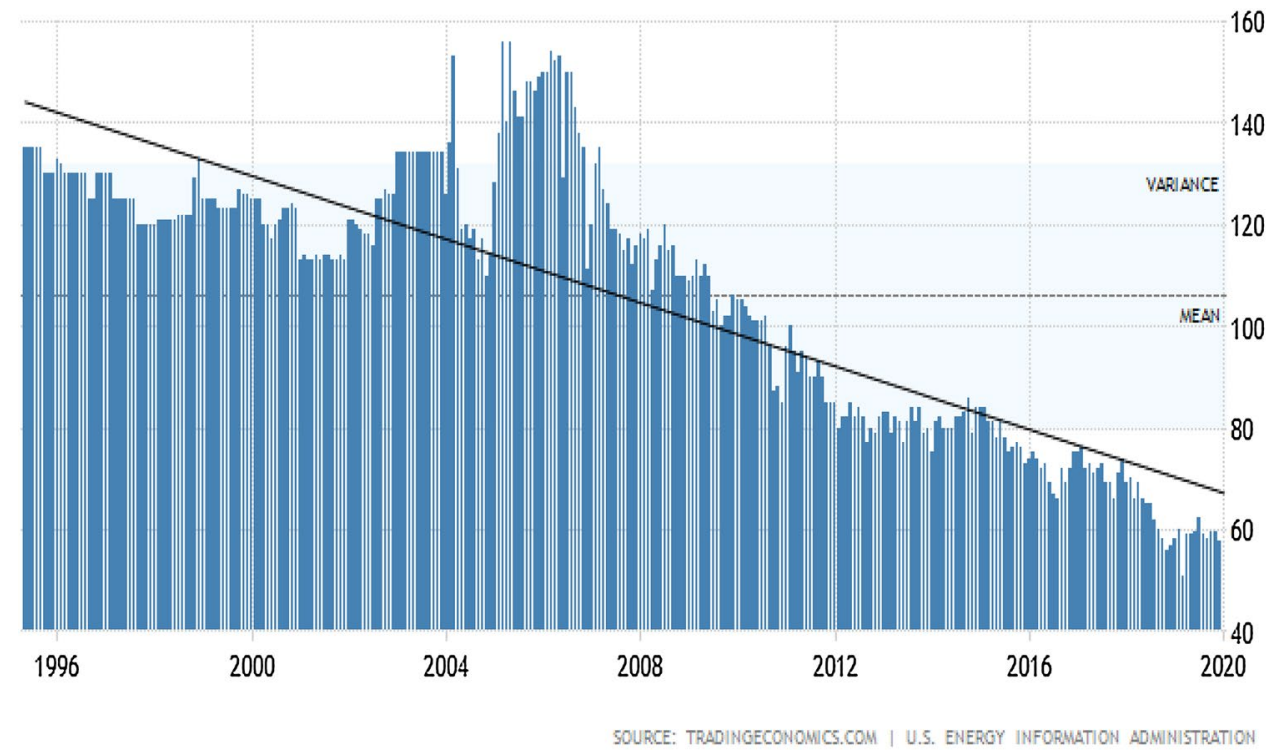

efficiency (Leonhardt et al. 2014; Fondevila Sancet et al. 2018). One of the challenges of this technique is the adsorption of polymer additives within the wells which results in a reduction in the viscosity of the polymer solution resulting in a reduction in sweep efficiency and oil recovery. The existence of thief zones or high permeability channels also results in the polymer solution bypassing key portions of the reservoir; however, the utilization of cross-linked polymers has been shown to mitigate this problem (van de Hoek et al. 2001).

In TT, a recent study conducted by Coolman et al. (2020) investigated the adsorption and viscosity characteristics of the polymer flooding additives xanthan gum and Aquagel on three different soil types, namely sand, Valencia clay (high iron) and Longdenville clay (low iron). The results offered conclusive evidence demonstrating the critical importance of the soil type and the pore structure characteristics of the soil that may be present in oil wells as it relates to the adsorption characteristics of the polymer flooding agents. Simulation models were generated using the EOR 4 well and showed that utilization of these two polymer flooding agents can produce higher levels of oil recovery compared to $\mathrm{CO}_{2}$ injection and waterflooding.

Despite the favourable results, polymer flooding fails to decrease residual oil saturation since the capillary number cannot be significantly increased due to the high polymer viscosity. The injection of an alkali such as $\mathrm{NaOH}$ can facilitate neutralization reactions in the crude oil to develop a soap which can increase the capillary number, reduce the interfacial tension and residual oil saturation. The result lower than required recovery factor $(1-6 \%)$ has been attributed to an associated lower degree of mobility control (Mayer et al. 1983; Sheng 2015; Sheng 2017). As highlighted by Sheng (2017), there is great potential for synergy utilizing an alkaline-polymer technique; however, despite the existence of some applications of alkaline-polymer flooding trials, the numbers have been few and more studies are necessary. Consequentially, this study aims to develop and evaluate an alkaline-xanthan gum polymer flooding technique to be used on the EOR 4 and other similar wells in Trinidad and Tobago in an effort to foster EOR efforts and mitigate the downward trend in crude oil production.

\section{Methodology}

\section{Raw materials}

Gravel packed sand used for the adsorption studies was obtained from a reservoir in Trinidad. Xanthan gum polymer material was provided by Baroid Trinidad Services limited.

\section{Adsorption studies}

The adsorption study was conducted according to Coolman et al. (2020). Working polymer solutions of concentrations of xanthan gum polymers $(500 \mathrm{ppm}, 1000 \mathrm{ppm}$, $2000 \mathrm{ppm}$ and $4000 \mathrm{ppm}$ ) representing typical dosages used in industry were mixed in various $\mathrm{NaOH}$ solutions at concentrations $(0.25 \%, 0.5 \% .1 \%$ and $2 \%)$. The corresponding absorbance readings were measured in the HACH DR 5000 UV-VIS spectrophotometer machine at the $\lambda_{\max }$ wavelength value $340 \mathrm{~nm}$ applicable to the xanthan gum polymer. The data obtained were used to generate calibration graphs for the xanthan gum polymer for the quantitation of the absorbed polymer on the gravel packed sand in subsequent experiments. 
The gravel pack sand was preheated before use at $150{ }^{\circ} \mathrm{C}$ for $3 \mathrm{~h}$. Samples $(1 \mathrm{~g})$ were mixed with solutions of the alkali-xanthan gum at the various concentrations and $\mathrm{pH}$. These mixtures were allowed to equilibrate for $24 \mathrm{~h}$ at ambient temperature before further analysis. The solutions were subsequently filtered, the absorbance of the unadsorbed polymer measured and the concentrations of the unabsorbed polymer in the filtrate calculated using the calibration curve.

\section{Viscosity studies}

As described by Coolman et al. (2020), the viscosities of the $500 \mathrm{ppm}, 1000 \mathrm{ppm}, 2000 \mathrm{ppm}$ and $4000 \mathrm{ppm}$ concentrations of xanthan gum polymer solutions at the various $\mathrm{pH}$ values were analysed using an OFITE Testing 8-speed Rotational viscometer. Measurements of viscosities were recorded for shear rates from 6 to $600 \mathrm{rpm}$. Values of shear stress, shear rate and viscosity were calculated using the following relationships:

Shear Stress, $\mathrm{lbf} / 100 \mathrm{ft}^{2}=1.067 \times \theta$.

Shear Rate, $\mathrm{s}^{-1}=\mathrm{RPM} \times 1.703$.

Viscosity, $\mathrm{Pa} \mathrm{s}^{-1}=\frac{\text { ShearStress }}{\text { ShearRate }}$

\section{Field description}

The purpose of this study is to investigate the effect of an alkaline-polymer flood on the oil recovery factor in a typical well in Trinidad. The well investigated in this project is the EOR 4 located in the Forest Reserve field in the southwest peninsula of the island of Trinidad (Fig. 2). The
Forest Reserve field is located on the southern flank of the east-northeast trending Fyzabad Anticline. The reservoirs were deposited under deltaic conditions and are highly heterogeneous and complex (Mohammad-Singh et al., 2004). Shale outs and faults and water-oil contacts define limits of individual oil accumulations and are illustrated in Fig. 3.

The data for EOR 4 used for the simulation modelling were obtained from work done by Mohammad-Singh et al. (2004); however, the model developed also included

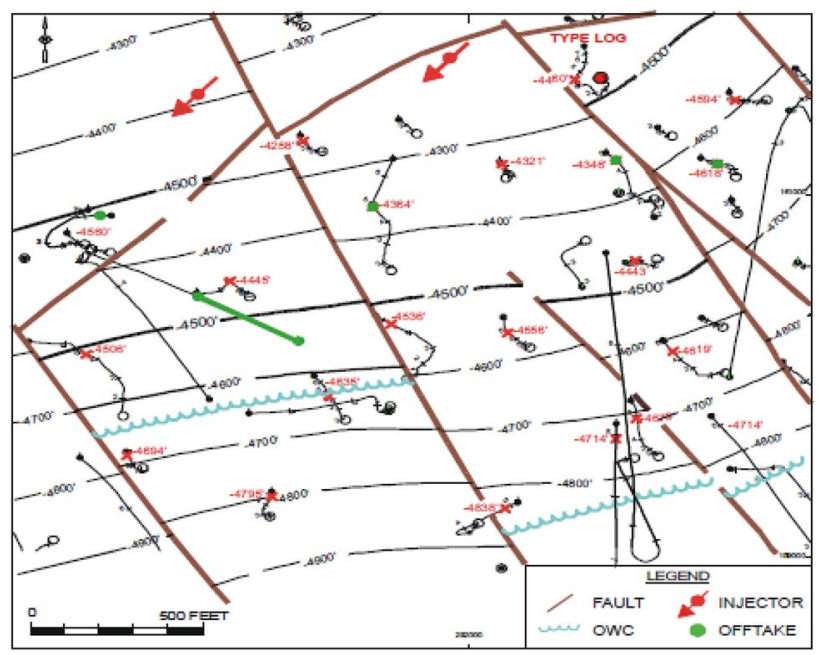

Fig. 3 Structure contour map, upper cruse sands-EOR 4 (Mohammad-Singh et al. 2004)
Fig. 2 Location of EOR 4 in Trinidad (Mohammad-Singh et al. 2004)

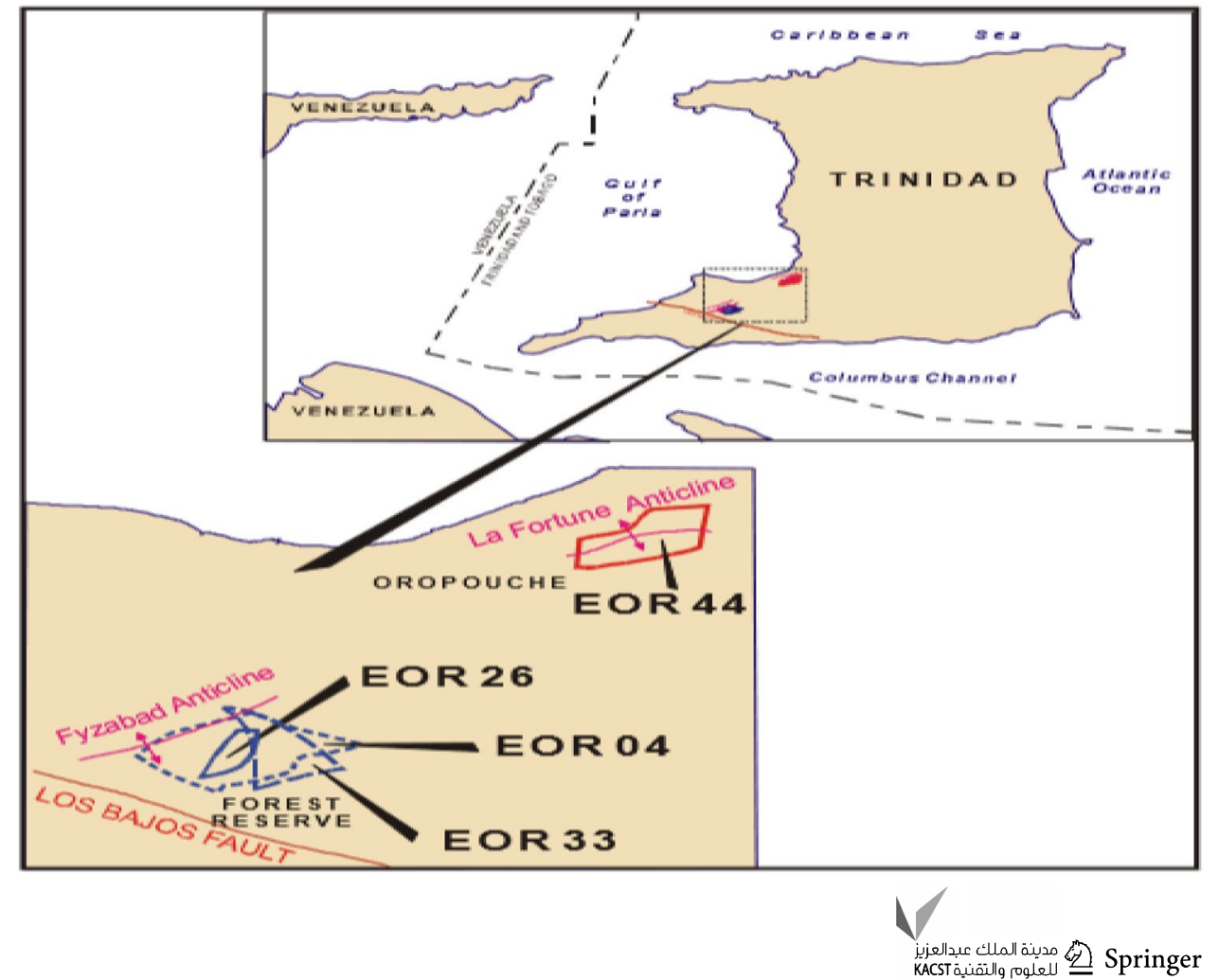


adsorption and viscosity data obtained from laboratory experiments conducted in this study.

\section{Screening criteria}

The unique characteristics in terms of reservoir parameters and fluid properties are key requirements in determining the suitability of an EOR strategy. In the study conducted by Coolman et al. (2020), the selection of the EOR 4 well to evaluate for the implementation a polymer flood was based on the fact that the reservoir data of the EOR 4 documented by Mohammad-Singh et al. (2004) fit the requirements of the general screening criteria for this type of EOR as stipulated by Taber et al. (1997) and Sheng (2015). The requirements for the use of an alkaline-polymer flood EOR also fit the required criteria, and Table 1 highlights some to the key required parameters that were satisfied justifying the suitability of the alkaline-polymer flood technique.

\section{Numerical modelling}

The field data presented in Table 2 and the results of the absorption and viscosity studies from the laboratory study were used to design the simulation models using commercial software Computer Modelling Group Limited software (CMG-STARS) and the results are shown in Figs. 4 and 5. The model was created to be 20,904 grid blocks in the $i$ direction (67 blocks 52 block in the j direction and 6 blocks in the $\mathrm{k}$ direction with each block being approximately 50 $\mathrm{ft}$ representing an area of 120 acres. The bubble point, fracture pressure, reservoir temperature, maximum pressure and oil density were $1343.13 \mathrm{psi}, 1604 \mathrm{psi}, 120^{\circ} \mathrm{F}, 5000 \mathrm{psi}$ and $29^{\circ} \mathrm{API}$, respectively. The water and oil saturations were 0.55 and 0.45 , respectively. Once the base case was developed, the Computer Modelling Intelligent Optimization \& Analysis Tool (CMOST-Al) was used to optimize the oil production from the simulation results.

Table 1 Showing a comparison of the required characteristics for alkaline-polymer EOR with the upper cruse sands (EOR 4) parameters

\begin{tabular}{lll}
\hline Parameter & Alkaline polymer & Upper cruse sands \\
\hline Depth, ft & $>2500$ & 4200 \\
Oil viscosity, cp & $<35$ & 6 \\
Gravity, API & $>20$ & 25 \\
Oil saturation, \%PV & $>35$ & 73 \\
Permeability, md & $>10$ & 334 \\
Formation type & Sandstone preferred & Mostly clean sand \\
Temperature $^{\circ} \mathrm{F}$ & $>80$ & 130 \\
\hline
\end{tabular}

Table 2 Reservoir data for EOR 4 well-forest reserve-(MohammadSingh et al. 2004)

\begin{tabular}{ll}
\hline Rock properties & EOR4 well \\
\hline Area (acs) & 120 \\
Pay zone & U. Cruse \\
Depth (ft) & 4200 \\
Thickness (ft) & 196 \\
Porosity (\%) & 31 \\
Permeability (mD) & 334 \\
Oil saturation (\%) & 73 \\
Temperature ( ${ }^{\circ}$ F) & 130 \\
Transmissibility (mD-ft/cp) & 5036 \\
Fluid properties & \\
Initial conditions & \\
$\quad$ Reservoir pressure (psi) & 2200 \\
Solution gas-oil ratio (scf/bbl) & 400 \\
Oil formation volume factor (bbl/bbl) & 1.16 \\
Oil gravity ( ${ }^{\circ}$ API) & 25 \\
Oil viscosity (cp) & 6 \\
At CO ${ }_{2}$ flood start & \\
Reservoir pressure (psi) & 650 \\
Solution gas-oil ratio (scf/bbl) & 70 \\
Oil formation volume factor (bbl/bbl) & 1.07 \\
Oil viscosity (cp) & 13 \\
\hline
\end{tabular}

\section{Results and discussion}

\section{Adsorption studies}

The standard solutions of various concentrations of the xanthan Gum polymer flooding compound at the different sodium hydroxide additions $(\mathrm{pH})$ were prepared, and the resulting calibration curves were plotted. Figure 6 shows a typical calibration curve obtained for the xanthan gum solution containing $1 \% \mathrm{NaOH}$.

The concentration of unadsorbed xanthan gum after equilibration was quantified using the relevant calibration curves as outlined by Coolman et al. (2020). The results as depicted in Fig. 7 show the variation in the amount of xanthan gum adsorbed by $1 \mathrm{~g}$ of gravel packed sand at different $\mathrm{pH}$ values. Generally speaking, the xanthan gum adsorbed on the substrate increased as the concentration of the $\% \mathrm{NaOH}$ increased with the $1000 \mathrm{ppm}$ xanthan gum mixture containing $0.25 \% \mathrm{NaOH}$ exhibiting the lowest adsorption capacity of all the samples tested.

The xanthan gum solutions containing $2 \% \mathrm{NaOH}$ generally exhibited the highest absorption capacity for the gravel packed sand, and the combination with the 4000 ppm xanthan gum blend demonstrated the highest adsorption capacity of all the samples analysed. 


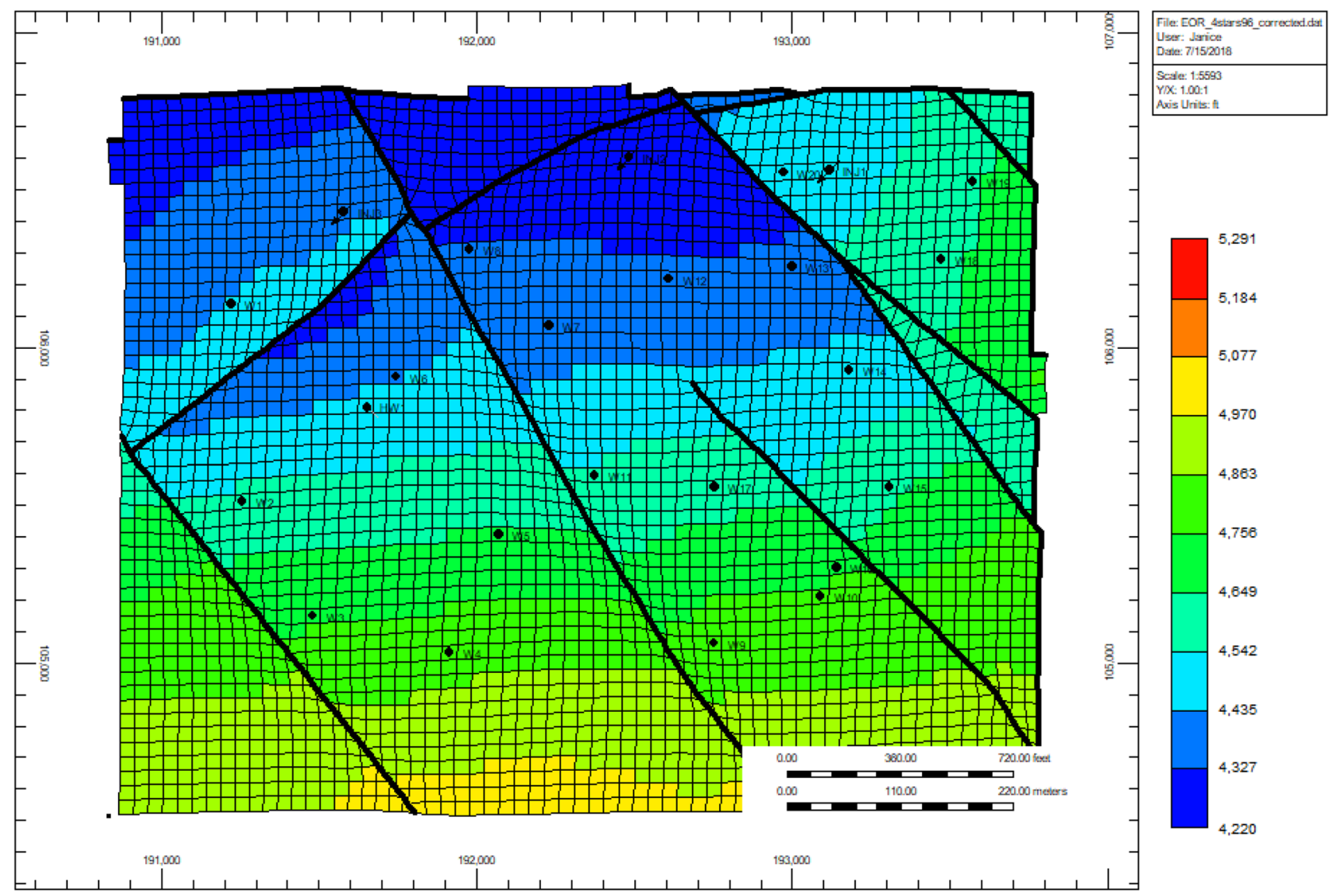

Fig. 4 Grid top view showing location of faults and wells for EOR-4 project

The influence of $\mathrm{pH}(\% \mathrm{NaOH})$ on the physico-chemical properties and adsorption characteristics of xanthan gum observed in this study is consistent with the previous work conducted by Rahmati et al. (2018). Rahmati et al. (2018) studied the thermodynamic compatibility and probable interactions between Speckled Sugar been protein (SSBP) and xanthan gum and found that as the $\mathrm{pH}$ was varied, the adsorption characteristics also varied due to the occurrence of different types of interactions between SSBP and xanthan. It was found that at lower $\mathrm{pH}$ values, electrostatic interactions and hydrogen bonding were predominant; however, as the $\mathrm{pH}$ was increased, phase separation and complex coacervation occurred as incompatibility or segregative phase behaviour became dominant. The $1 \% \mathrm{NaOH}$ demonstrated the highest adsorption capacity.

\section{Viscosity studies}

The variations in the viscosity of $1000 \mathrm{ppm}$ xanthan gum with shear rate for different $\mathrm{NaOH}$ additions (alkalinity) are shown Fig. 8. These trends were representative of all the different blends of xanthan gum of various polymer concentrations.
The results indicate that for all the shear rates, the higher the alkalinity of the alkali-polymer flood solution, the higher the viscosity. The importance of this viscosity data in the prediction of the suitability of the use of alkali-polymer flooding in EOR for a particular well cannot be underscored. As described by Glatz (2013), the mobility ratio (M) is the ratio of mobility $(\lambda)$ of the displacing fluid (water) to the mobility of the displaced fluid (oil), where mobility is permeability $(\kappa)$ divided by viscosity $(\mu)$ and is dependent on the volumetric sweep efficiency. If $\mathrm{M}$ is greater than 1 , instability will occur giving rise to "viscous fingering" which occurs if there is a large viscosity difference between the displacing and displaced oil leading to poor recovery. If $\mathrm{M}$ is less than one, due to the use of polymer flooding, for example, the viscosity of displacing fluid is feasible, minimizing fingering, hence increasing the EOR process. As explained by Brunchi et al. (2016), the inherent interactions within xanthan gum in its primary structure and the existence of a double helix configuration in its secondary structure can account for differences in its rheological behaviour as evidenced by differences in viscosities observed as $\mathrm{pH}$ is varied. As explained by Brunchi et. al., (2016), in a more acidic environment, xanthan gum chains become 


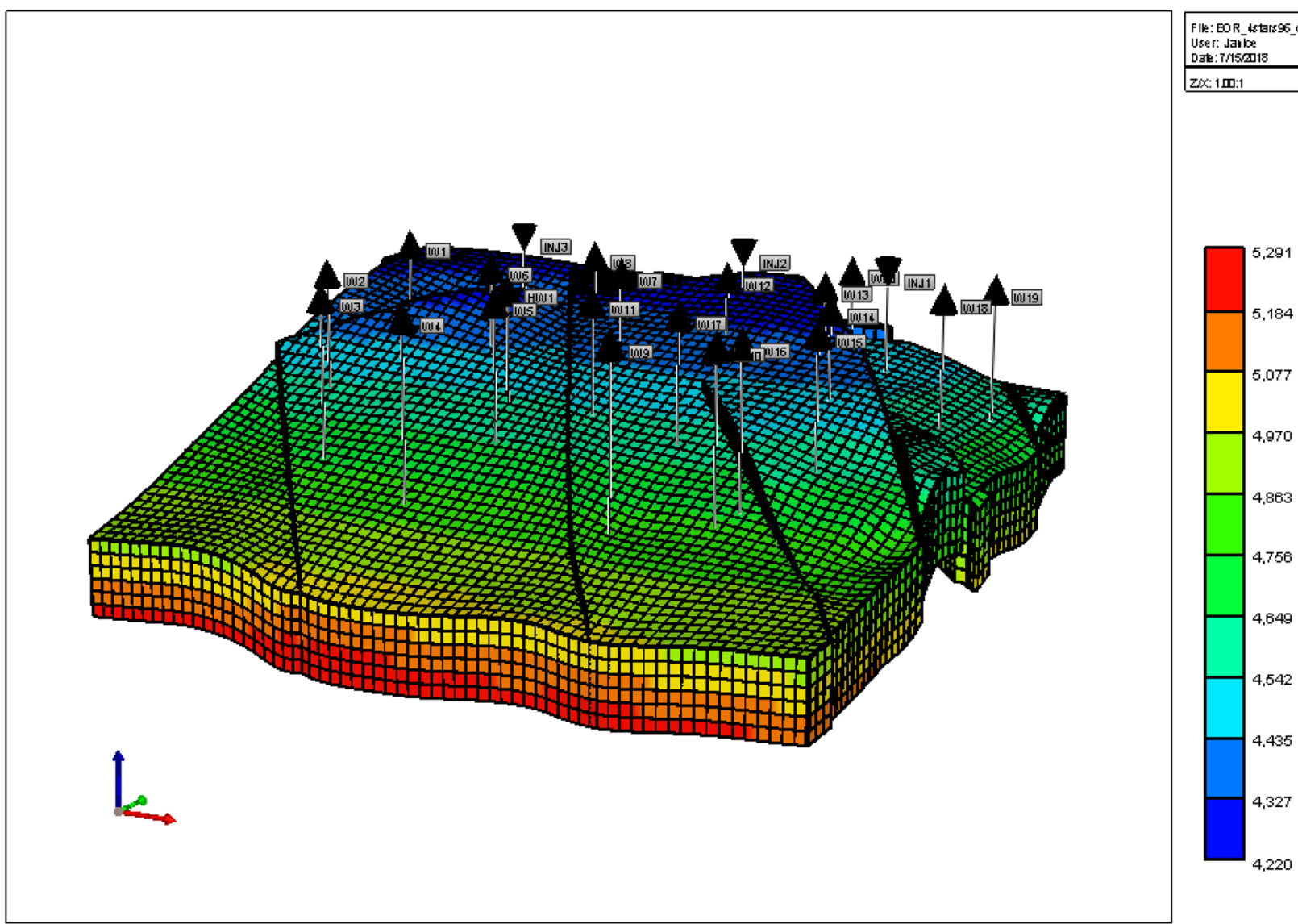

Fig. 5 3D view of reservoir model for EOR 4

Fig. 6 Typical calibration curve at $\lambda_{\max } 340 \mathrm{~nm}$ for xanthan gum polymer solution containing $1 \%$ $\mathrm{NaOH}$

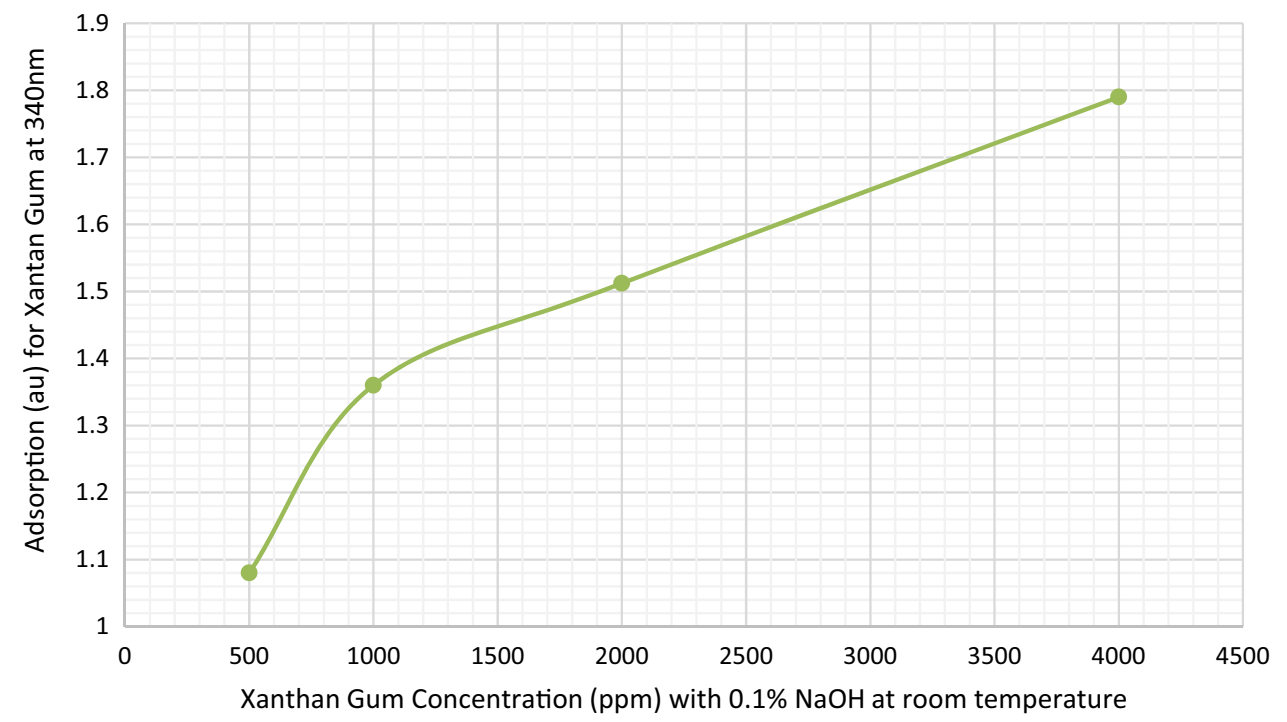

uncharged and partially flexible and as acidity decreases, so does the level of protonation which results in electrostatic repulsive forces between - $\mathrm{COO}$ - groups facilitating chains expansion. In acidic conditions, the xanthan gum chains conformation is double helix and as the alkalinity increases, the chains undergo conformational changes resulting in the 
Fig. 7 Variation in the amount of xanthan gum adsorbed on $1 \mathrm{~g}$ of sand for different $\mathrm{NaOH}$ additions (alkalinity)

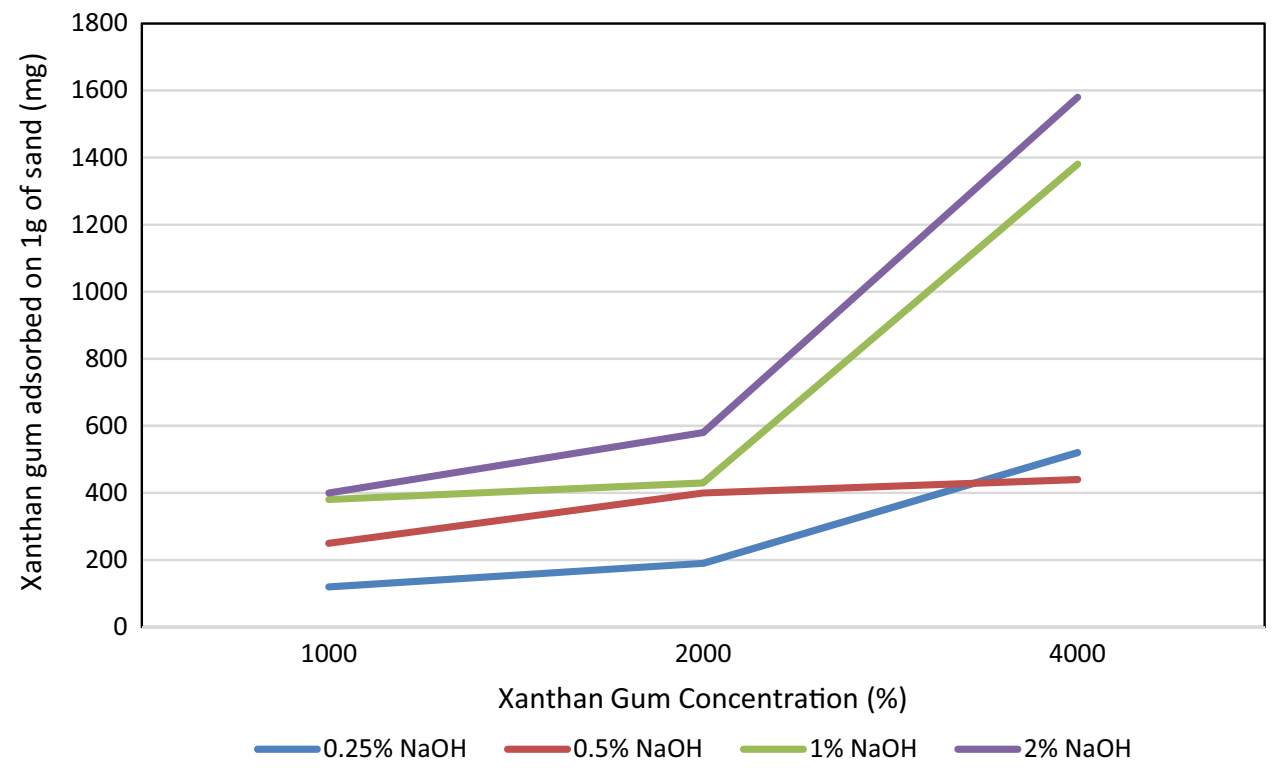

Fig. 8 Variation in the viscosity of $1000 \mathrm{ppm}$ xanthan gum with shear rate for different $\mathrm{NaOH}$ additions (alkalinity)

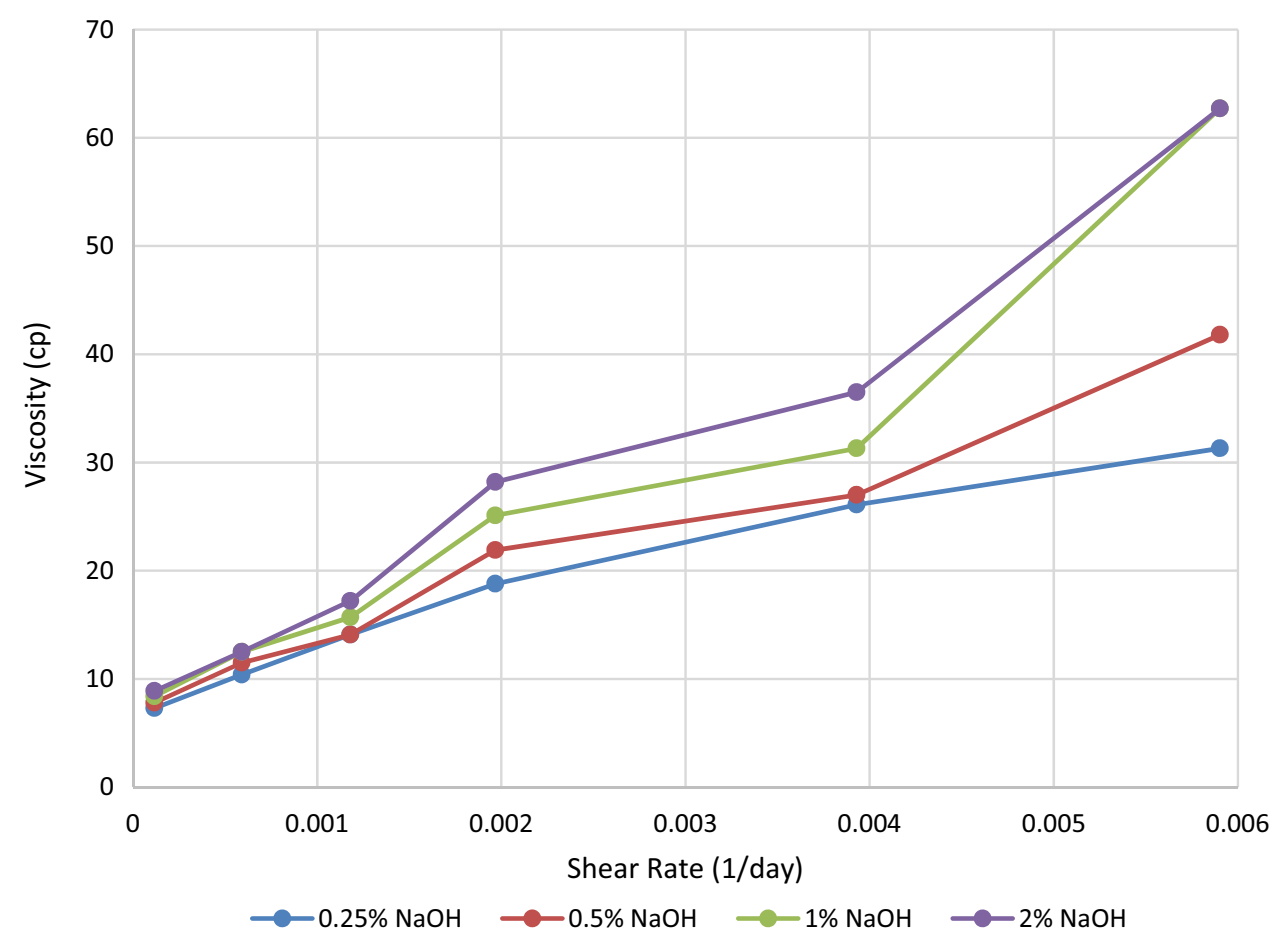

transformation of the double helical to coils in disordered state resulting in increases in viscosity. Research by Brunchi et al. (2016) represented in Fig. 9 shows the conformational transitions of the xanthan gum chains due to increasing $\mathrm{pH}$ and other parameters such as temperature, and ionic strength causes a change in physical and rheological properties of the polymer structure from a rigid state (lower viscosity) to a more flexible conformation in a disordered state (higher viscosity).
The findings of adsorption and viscosity studies by Coolman et al. (2020) supported the findings of Anovitz and Cole (2015), Saleh (2015a, b, 2016) and Alvarez et al. (2018) which offered conclusive evidence of the key importance that the pore structure characteristics, morphology and porosity of the soil present in oil wells as well as the type of additive are used to play in determining the physical properties of the system, how they interact with stored fluid in them in terms of absorption characteristics, flow, precipitation and 


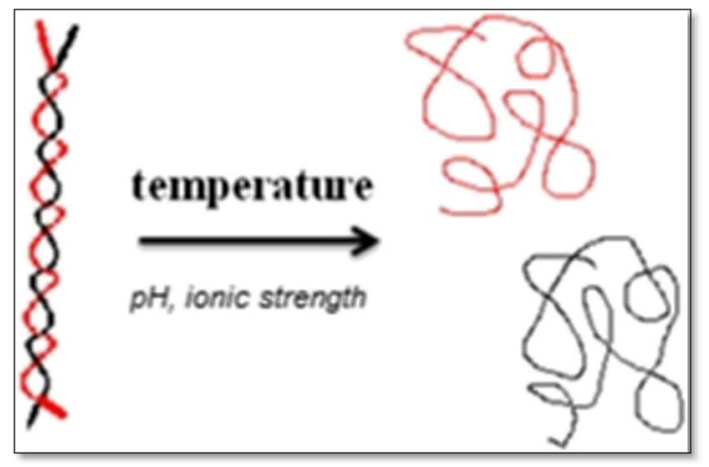

Fig. 9 Conformational transitions of xanthan gum in aqueous solutions

reactions. This study while offering conclusive evidence supporting the findings of these researchers went one step further by offering key data regarding the influence of $\mathrm{pH}$ on the adsorption characteristics of xanthan gum. The data derived from this absorption study will be factored in the subsequent simulation protocols for the evaluation of an alkali-EOR polymer flooding strategy of EOR 4.

\section{Simulation results}

The simulation models were run for a 10-year period where the alkaline-polymer flood was implemented for one year followed by waterflooding for 9 years using the $0.25 \% \mathrm{NaOH}$ $1000 \mathrm{ppm}$ xanthan gum. Three different injection rates were evaluated 500, 1000 (labelled A) and 1500 (labelled B) bbls/ day for optimization to achieve maximum displacement and minimize viscous fingering. The results as shown in Fig. 10 show that as the injection rate increases, the oil recovery factor increases incrementally also.
There have been numerous mechanisms suggested to explain alkaline flooding, and they include emulsification and entrainment, emulsification and entrapment, wettability reversal (oil-wet to water-wet, or water-wet to oil-wet), emulsification and coalescence (Sheng 2015). The common feature of these mechanisms is that they involve the in situ formation of soap. The total acid number of TAN is a value of measure of the potential of a crude oil to form soap or surfactants and is basically the mass of potassium hydroxide $(\mathrm{KOH})$ in milligrams that is required to neutralize one gram of crude oil. As outlined by Chan et. al., (2006), TAN values $>1.0$ are generally considered high, $0.3-1$ is intermediate, and $0.1-0.25$ is considered low. They found that the majority of crude oils have acid number lower than $5 \mathrm{mg} \mathrm{KOH} / \mathrm{g}$ oil, and the minimum value of $0.3 \mathrm{mg} \mathrm{KOH} / \mathrm{g}$ in oil is required for alkali flooding applications. The injection of an alkali such as $\mathrm{NaOH}$ results in neutralization reactions with the saponifiable chemicals in the crude oil to develop the soap which reduces the interfacial tension and residual oil saturation. The crude oil in reservoirs such as EOR 4 has an oil value API around 19 and a TAN value $>1$ (Mohammad-Singh et. al., 2004,), and it is intuitive to infer that EOR 4 should facilitate an incremental increase in oil recovery with the addition of increasing amounts of $\mathrm{NaOH}$.

The oil recovery rates for alkaline polymer flooding scenarios were run for a 10-year period (2005-2015), and the incremental increase in the recovery factors for the scenarios is shown in Table 3.

As depicted in Table 3, it was observed that the implementation of an alkali polymer flooding did result in an incremental increase in the recovery factors (approximately $3 \%$ ) when compared to the values of polymer flooding technique alone. This observation was consistent with the previous work done (Mayer et al. 1983; Sheng 2015, 2017). The
Fig. 10 Recovery factor for different injection rates (using the $0.25 \% \mathrm{NaOH} 1000 \mathrm{ppm}$ xanthan gum

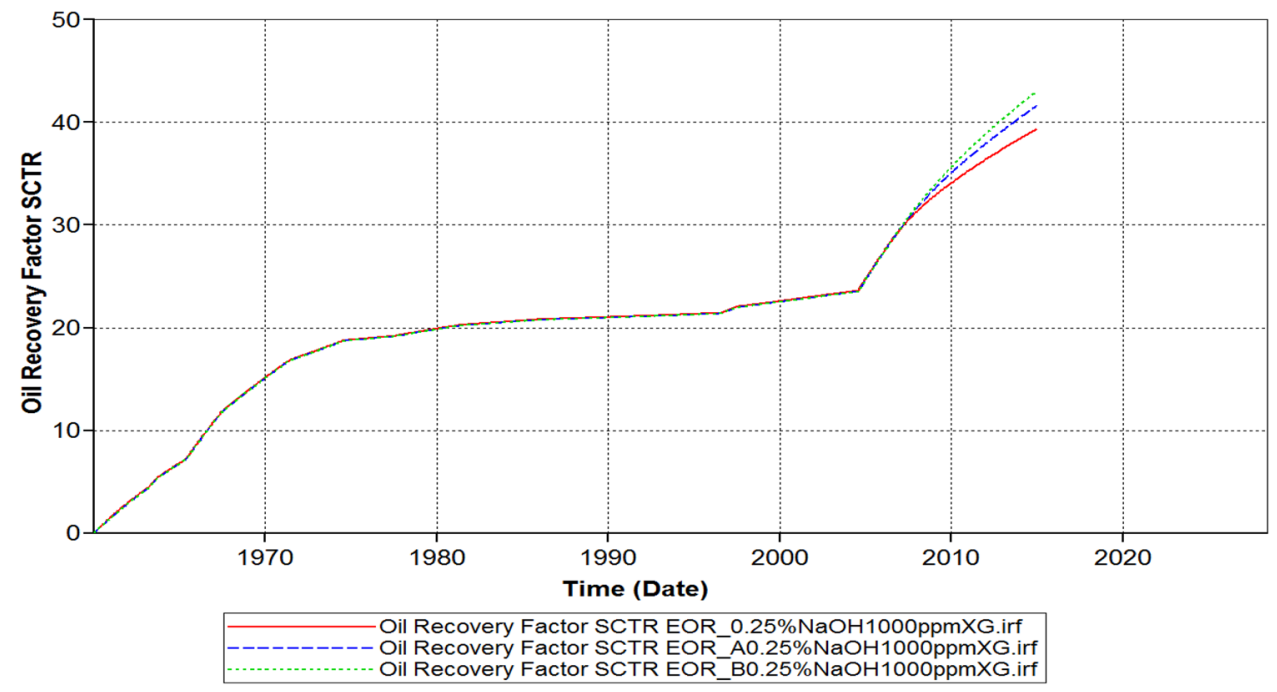


Table 3 Oil recovery rates for alkaline polymer flood scenarios

\begin{tabular}{lllllll}
\hline EOR method & $0 \% \mathrm{NaOH} 1000 \mathrm{ppm}$ polymer & $\begin{array}{l}0 \% \mathrm{NaOH} \\
2000 \mathrm{ppm} \\
\text { polymer }\end{array}$ & $\begin{array}{l}0.25 \% \mathrm{NaOH} \\
1000 \mathrm{ppm} \\
\text { polymer }\end{array}$ & $\begin{array}{l}0.25 \% \mathrm{NaOH} \\
2000 \mathrm{ppm} \\
\text { polymer }\end{array}$ & $\begin{array}{l}0.5 \% \mathrm{NaOH} \\
1000 \mathrm{ppm} \\
\text { polymer }\end{array}$ & $\begin{array}{l}0.5 \% \mathrm{NaOH} \\
2000 \mathrm{ppm} \\
\text { polymer }\end{array}$ \\
\hline Cum. prod (bbl) & $6,670,703$ & $6,787,870$ & $6,686,833$ & $6,717,780$ & $6,660,203$ \\
OOIP (bbl) & $36,512,400$ & $36,512,400$ & $36,512,400$ & $36,512,400$ & $36,512,400$ & $36,745,650$ \\
Recovery Factor & 14.95 & 15.52 & 18.31 & 18.4 & 18.24 & 18.47 \\
\begin{tabular}{l}
$(\%)$ \\
\hline
\end{tabular} & & & & & \\
\hline
\end{tabular}

interesting observation is that despite an increase in $\mathrm{NaOH}$ levels from 0.25 to $0.5 \%$ at the both xanthan gum concentrations of $1000 \mathrm{ppm}$ and $2000 \mathrm{ppm}$, the recovery factors were similar and a significant change in the oil recovery as a function of the alkaline and the fluid viscosity was not observed. An explanation for this observation was suggested by Sheng (2015) who found that only a fraction (as low as one third) of acids in the crude oil can be converted to in situ surfactant (soap) responsible for the overall incremental oil recovery in alkaline flooding to be low, consistent with observations with the field projects. Sheng (2015) suggested that not all acid moieties may facilitate soap generation as it exists in fixed amounts and that salinity conditions may have to be optimized for effective soap generation. This suggestion can account for our observation that incremental additions of $\mathrm{NaOH}$ beyond the $0.25 \%$ level resulted in insignificant changes in recovery factors as the acidic moieties available for saponification were exhausted. It was suggested in the research that synthetic surfactant may need to be incorporated in the injection protocol to improve the phase behaviour and that the mechanism of emulsification instead of changes in IFT may not be the dominant mechanism in alkaline flooding.

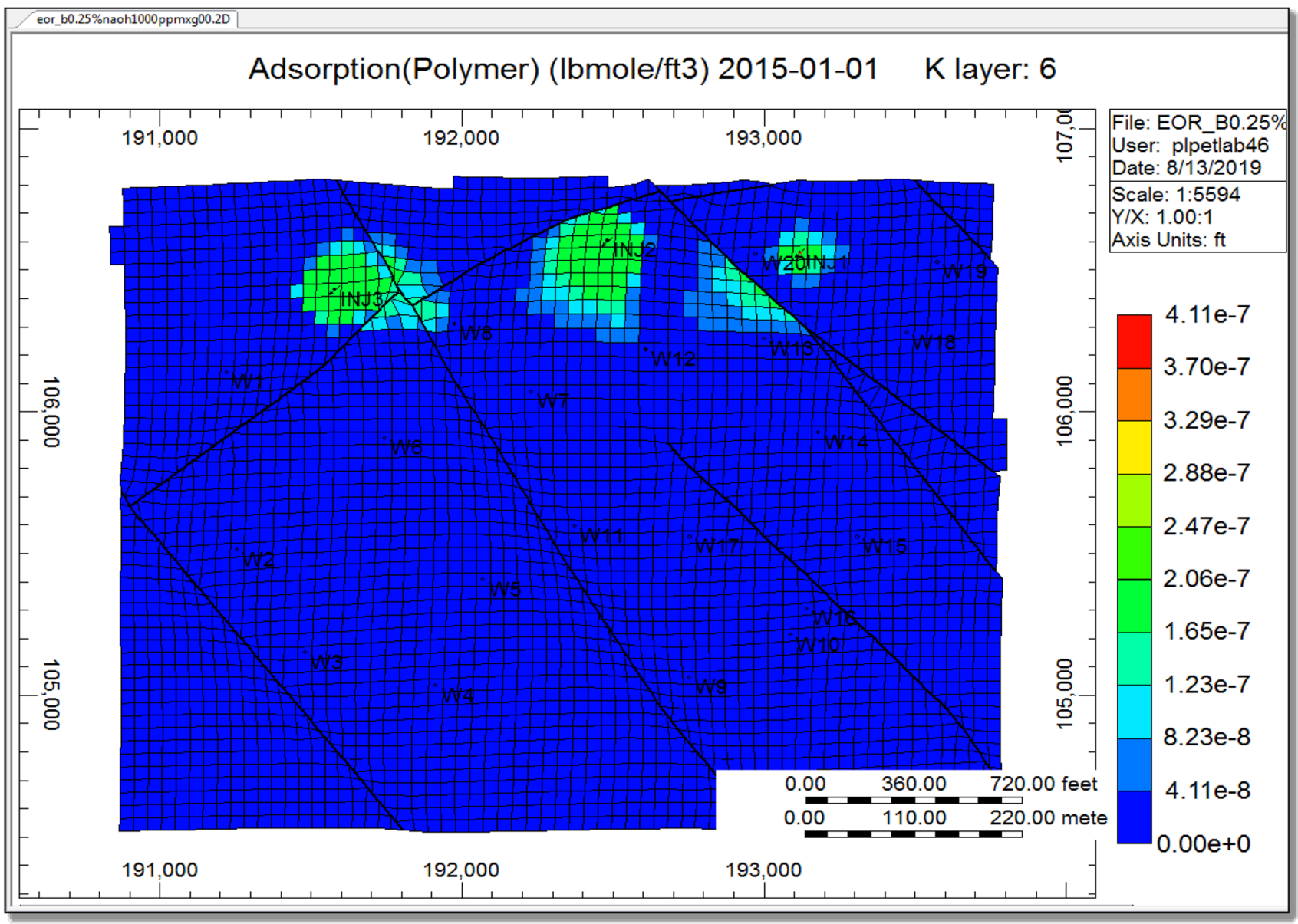

Fig. 11 Adsorption of 1000 ppm Polymer with $0.25 \% \mathrm{NaOH}$ 


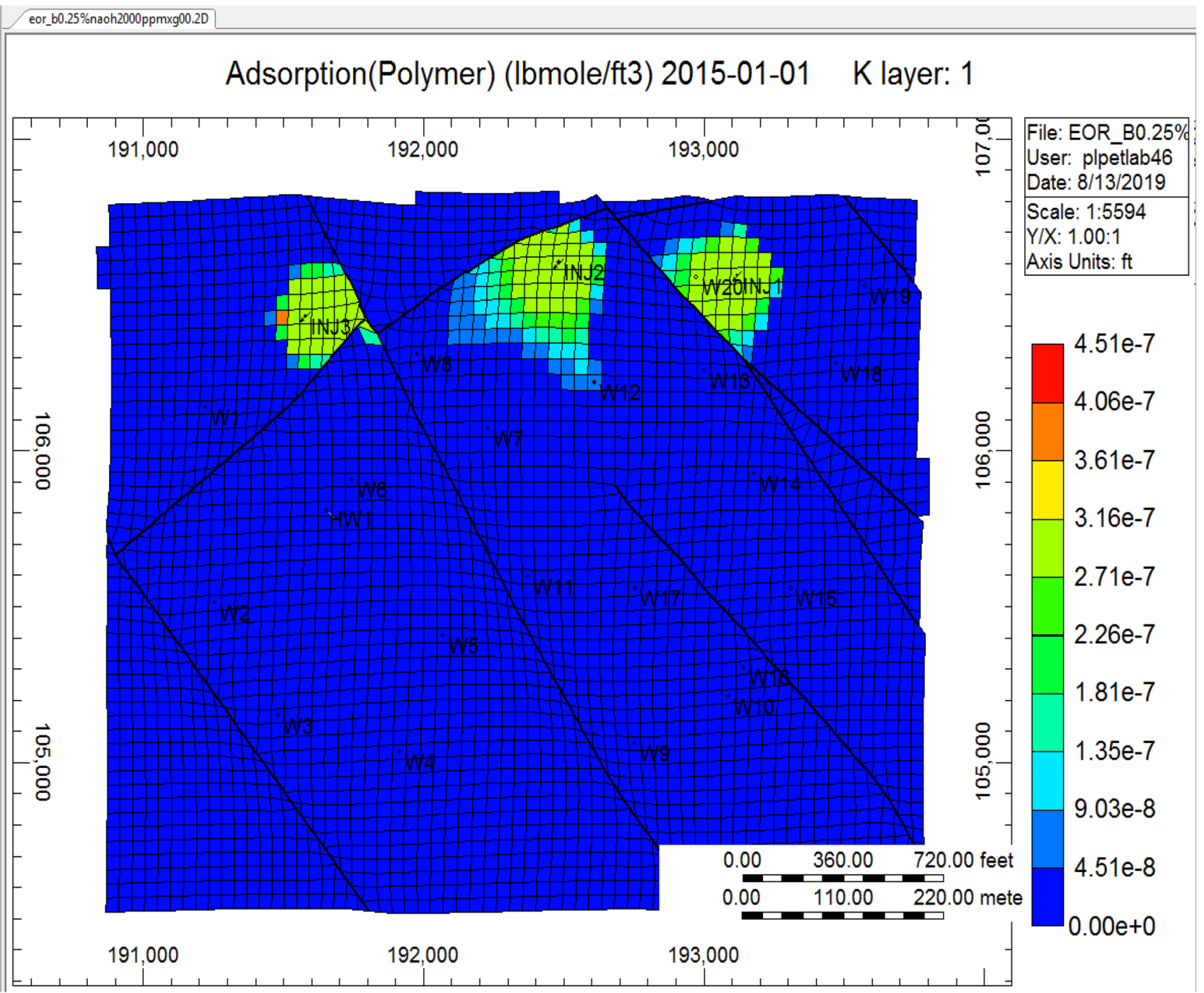

Fig. 12 Adsorption of 2000 ppm Polymer with $0.25 \% \mathrm{NaOH}$

\section{Analysing the alkaline polymer at an injection rate of $500 \mathrm{bbl} / \mathrm{day}$}

Figures 11, 12, 13, 14 and 15 show the distribution of the adsorption of polymer in the reservoir after the 10-year period. Alkaline polymer injection starts in the first year followed by 9 years of water injection.

The adsorption of $1000 \mathrm{ppm}$ xanthan gum polymer with $0.25 \% \mathrm{NaOH}$ is shown in Fig. 11, and the results illustrate that the average adsorption at the end of the 10 years was $2.27 \times 10^{-7} \mathrm{lbmole} / \mathrm{ft}^{3}$. It can be seen that not much polymer is adsorbed onto the formation as compared to the other concentration of xanthan gum and sodium hydroxide. Also, polymer was adsorbed on the other side of the faults, indicating that it has move further and closer to the producing well.
The adsorption of $2000 \mathrm{ppm}$ xanthan gum polymer with $0.25 \% \mathrm{NaOH}$ is shown in Fig. 12, and the illustration for this scenario shows that the average adsorption at the end of the 10 years was higher in comparison with the $0.25 \% \mathrm{NaOH}$ and $1000 \mathrm{ppm}$ of xanthan gum. In injected well 3, more polymer was adsorbed onto the formation. Also, the polymer adsorbed barely penetrated the other side of the faults, indicating that it may be more viscous due to an increase in concentration of the xanthan gum from 1000 to $2000 \mathrm{ppm}$.

The adsorption when $1000 \mathrm{ppm}$ xanthan gum containing $0.5 \% \mathrm{NaOH}$ was utilized is illustrated in Fig. 13. The illustration shows that the average adsorption at the end of the 10 years was even higher in comparison with the $0.5 \%$ $\mathrm{NaOH}$ and $1000 \mathrm{ppm}$ of xanthan gum as in the injected well 3, more polymer was adsorbed onto the formation. Additionally, the study shows that the polymer adsorbed 


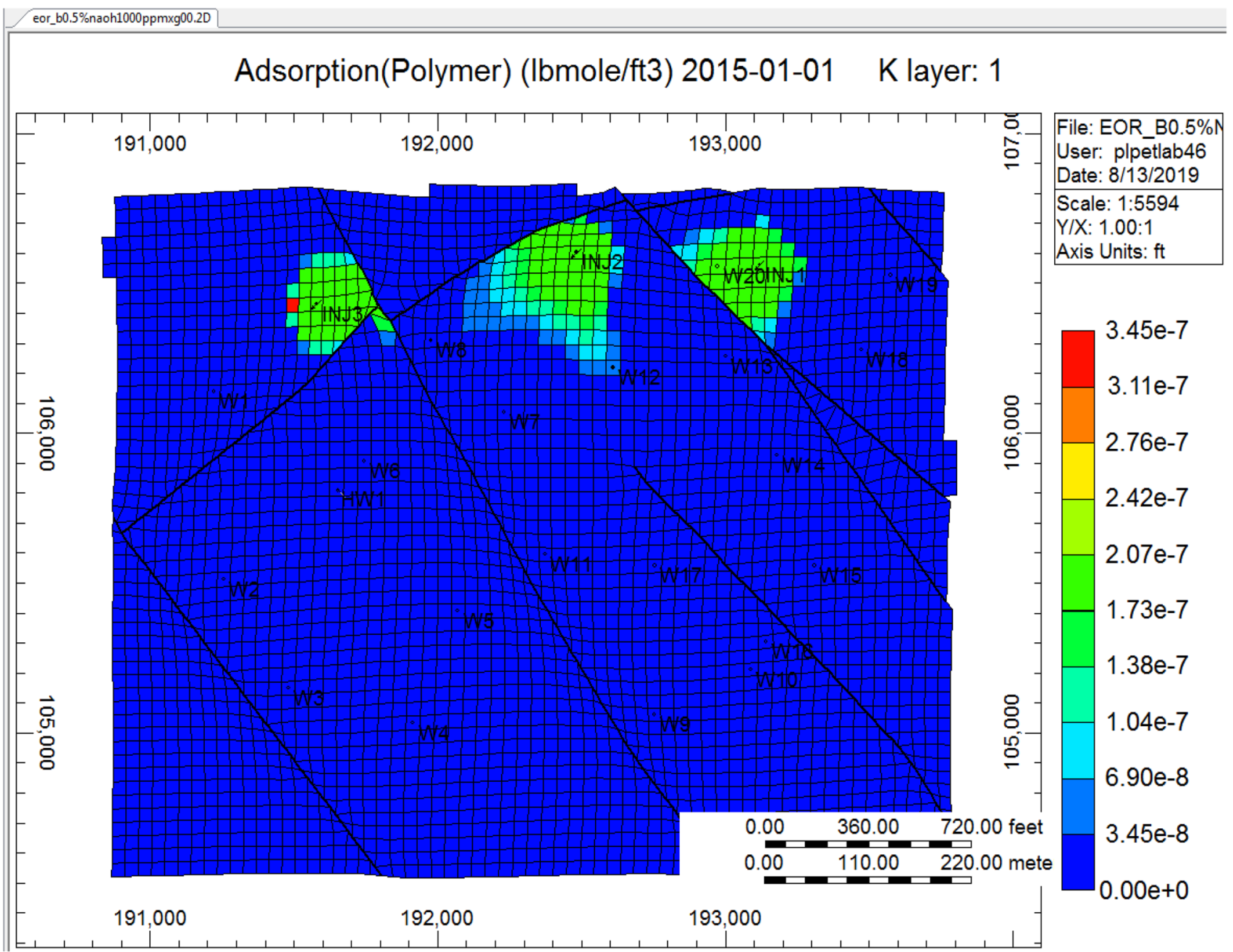

Fig. 13 Adsorption of 1000 ppm Polymer with $0.5 \% \mathrm{NaOH}$

barely penetrated the other side of the faults, which can be associated with the inherently higher viscosity associated with this formulation (more viscous due to an increase in $\mathrm{NaOH}$ concentration when compared to $0.25 \% \mathrm{NaOH}$ ).

The results of the final scenario which observed the adsorption of the $2000 \mathrm{ppm}$ polymer with $0.5 \% \mathrm{NaOH}$ is illustrated in Fig. 14. The results show that the average adsorption at the end of the 10-year period was lower in comparison with the $0.5 \% \mathrm{NaOH}$ and $1000 \mathrm{ppm}$ of xanthan gum. In injected well 3, more polymer was adsorbed onto the formation compared to the adsorption of the $1000 \mathrm{ppm}$ xanthan gum polymer with $0.25 \% \mathrm{NaOH}$. Again in this case, the polymer adsorbed barely entered the other side of the faults, indicating that it may have a relatively high resistance to flow.

The simulated oil recovery rates as well as the observed variations in the distribution of the adsorption of polymer in the reservoir after the 10-year period of treatment for the various alkaline-polymer flood scenarios are consistent with the data obtained from the preliminary adsorption and viscosity experimentation of this study. This study offers conclusive evidence and validation that variables such as soil type of a well (pore structure, morphology and porosity), additive type, chemical characteristics $(\mathrm{pH})$, adsorption characteristics as well as rheological (flow) characteristics are key factors in determining how a flooding system interacts with stored fluid in them. The interplay of these variables and the resulting conditions determine the conformational structure of the xanthan gum chains (double helix or coils in disordered state) resulting changes in the performance characteristics of the flooding system. Data from the laboratory studies provided key input data for the simulation software to produce near realistic EOR projections and for the evaluation of an alkaliEOR polymer flooding strategy of EOR 4. 


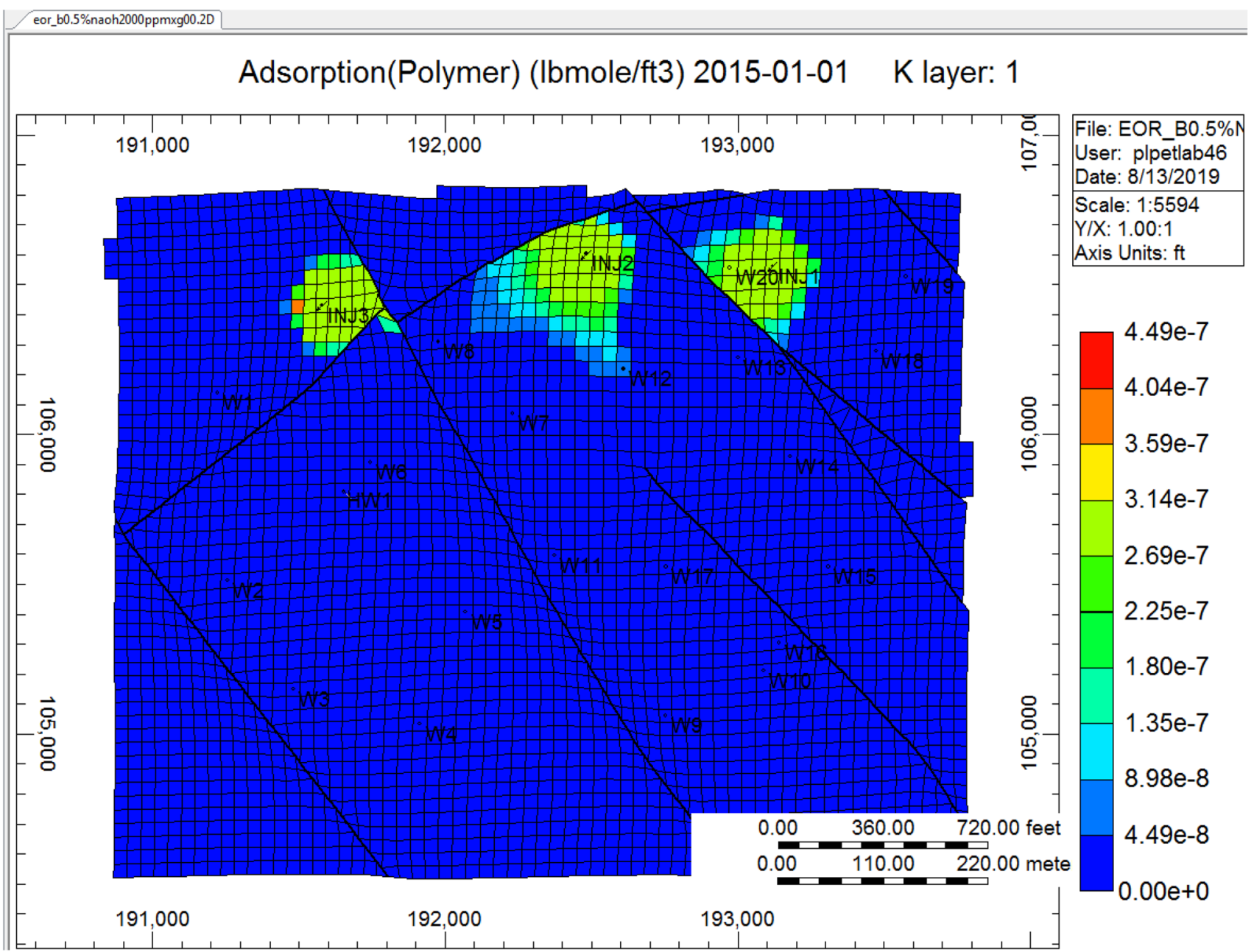

Fig. 14 Adsorption of 2000 ppm Polymer with $0.5 \% \mathrm{NaOH}$

Table 4 Projected economic performance of the various EOR flooding scenarios and oil price sensitivity analysis

\begin{tabular}{|c|c|c|c|c|c|c|c|c|c|}
\hline \multirow[t]{2}{*}{ Method } & \multicolumn{3}{|l|}{$\$ 35$ USD } & \multicolumn{3}{|l|}{$\$ 50$ USD } & \multicolumn{3}{|l|}{$\$ 60$ USD } \\
\hline & NPV (US\$ mm) & $\operatorname{IRR}(\%)$ & $\begin{array}{l}\text { Payback } \\
\text { month/ } \\
\text { year }\end{array}$ & NPV (US\$ mm) & $\operatorname{IRR}(\%)$ & $\begin{array}{l}\text { Payback } \\
\text { month/ } \\
\text { year }\end{array}$ & NPV (US\$ mm) & $\operatorname{IRR}(\%)$ & $\begin{array}{l}\text { Payback } \\
\text { month/ } \\
\text { year }\end{array}$ \\
\hline $\begin{array}{l}0.25 \% \mathrm{NaOH} 1000 \mathrm{ppm} \\
\quad \mathrm{XG}\end{array}$ & 19.92 & 23.70 & Mar-08 & 22.48 & 28.20 & Oct-07 & 32.56 & 44.30 & Dec-06 \\
\hline $\begin{array}{l}0.25 \% \mathrm{NaOH} 2000 \mathrm{ppm} \\
\quad \mathrm{XG}\end{array}$ & 18.92 & 17.40 & Dec-08 & 21.54 & 21.90 & May-08 & 31.72 & 37.10 & Apr-07 \\
\hline $\begin{array}{l}0.5 \% \mathrm{NaOH} 1000 \mathrm{ppm} \\
\quad \mathrm{XG}\end{array}$ & 17.37 & 12.90 & Oct-09 & 19.95 & 17.40 & Dec-08 & 30.03 & 32.50 & Jun-07 \\
\hline $\begin{array}{l}0.5 \% \mathrm{NaOH} 2000 \mathrm{ppm} \\
\quad \mathrm{XG}\end{array}$ & 16.2 & 9.10 & Oct-10 & 18.83 & 13.60 & Sep-09 & 29.11 & 28.90 & Oct-07 \\
\hline
\end{tabular}

The simulated economic analysis clearly shows that all the analysed EOR scenarios resulted in economically feasible outcomes of NPV, IRR and payback period for oil price variations between $\$ 35$ and $\$ 60$ USD per barrel of oil. A comparison of the individual strategies shows that the alkali-polymer flood system utilizing $0.25 \% \mathrm{NaOH}$ with $1000 \mathrm{ppm}$ xanthan gum polymer was the most economically feasible method at all oil prices analysed 


\section{Economic analysis}

The production data from the CMG simulation results for the different scenarios at the beginning of each year from 2005-2015 were analysed. A combination of the assumptions, cumulative oil production and cumulative net cash flow was used to calculate the year of payback, NPV and IRR for each scenario. Table 4 shows the projected economic performance of the various EOR flooding scenarios and a sensitivity analysis with respect to variations to oil prices.

\section{Conclusion}

An alkaline-xanthan gum polymer flooding technique was developed to be used in EOR4 in TT. Adsorption studies showed that the $1000 \mathrm{ppm}$ xanthan gum flooding solution containing $0.25 \% \mathrm{NaOH}$ exhibited the lowest absorption capacity and viscosity for the gravel packed sand. Simulation studies showed that the adsorption of 1000 ppm xanthan gum polymer with $0.25 \% \mathrm{NaOH}$ at the end of the 10 years was $2.27 \times 10^{-7} \mathrm{lbmole} / \mathrm{ft}^{3}$. The simulated economic analysis showed that this alkali-polymer flood formulation was the most favourable in terms of cumulative production, recovery factor, net present value (NPV), Internal Rate of Return (IRR) and time to payback. This study provides required information and data to justify that an alkali-EOR polymer flooding strategy of EOR 4 is a feasible initiative.

Open Access This article is licensed under a Creative Commons Attribution 4.0 International License, which permits use, sharing, adaptation, distribution and reproduction in any medium or format, as long as you give appropriate credit to the original author(s) and the source, provide a link to the Creative Commons licence, and indicate if changes were made. The images or other third party material in this article are included in the article's Creative Commons licence, unless indicated otherwise in a credit line to the material. If material is not included in the article's Creative Commons licence and your intended use is not permitted by statutory regulation or exceeds the permitted use, you will need to obtain permission directly from the copyright holder. To view a copy of this licence, visit http://creativecommons.org/licenses/by/4.0/.

\section{References}

Alvarez JO, Saputra IWR, Schechter DS (2018) December 1). The Impact of surfactant imbibition and adsorption for improving oil recovery in the wolfcamp and eagle ford reservoirs. Soc Pet Eng. https://doi.org/10.2118/187176-PA

Anovitz L, Cole DR (2015) Characterization and analysis of porosity and pore structures. Rev Mineral Geochem 80(4):61-164

Brunchi C-E, Bercea M, Morariu S, Dascalu M (2016) Some properties of xanthan gum in aqueous solutions: effect of temperature and pH. J Polym Res. https://doi.org/10.1007/s10965-016-1015-4

Coolman T, Alexander D, Maharaj R et al (2020) An evaluation of the enhanced oil recovery potential of the xanthan gum and aquagel in a heavy oil reservoir in Trinidad. J Petrol Explor Prod Technol. https://doi.org/10.1007/s13202-020-00878-5

Fondevila Sancet, G., Goldman, M., Buciak, J. M., Varela O, Fascio M, Manzano V, Luong M (2018) SPE-190408-MS molecular structure characterization and interaction of a polymer blend of xanthan gum-polyacrylamide to improve mobility-control on a mature polymer flood. Retrieved from https://www-onepetroorg.research.library.u.tt/download/conference-paper/SPE-19040 8-MS?id=conference-paper\%2FSPE-190408-MS

Glatz G (2013) A primer on enhanced oil recovery. Physics 240, Stanford University, Fall 2013.

Leonhardt B, Ernst B, Reimann S, Steigerwald A, Holding GmbH W (2014) SPE-169032-MS field testing the polysaccharide schizophyllan: results of the first year. Retrieved from https://wwwonepetro-org.research.library.u.tt/download/conference-paper/ SPE-169032-MS?id=conference-paper\%2FSPE-169032-MS

Mayer EH, Berg RL, Carmichael JD, Weinbrandt RM (1983) Alkaline injection for enhanced oil recovery - a status report. J Petrol Technol 35(1):209-221

Ministry of Energy and Energy Industries (2019) Retrieved from historical facts on the petroleum industry of Trinidad and Tobago: https://www.energy.gov.tt/historical-facts-petroleum/

Mohammad-Singh L, Singhal J, Ashok K (2004) Lessons from Trinidad's CO2 immiscible pilot projects 1973-2003. Retrieved from https://www-onepetro-org.research.library.u.tt/download/confe rence-paper/SPE-89364-MS?id=conference-paper\%2FSPE-89364 -MS

Rahmati NF, Koocheki A, Varidi M, Kadkhodaee R (2018) Thermodynamic compatibility and interactions between Speckled Sugar bean protein and xanthan gum for production of multilayer $\mathrm{O} / \mathrm{W}$ emulsion. J Food Sci Technol 55(3):1143-1153. https://doi. org/10.1007/s13197-017-3030-9

Saleh TA (2015a) (a). Isotherm, kinetic, and thermodynamic studies on $\mathrm{Hg}(\mathrm{II})$ adsorption from aqueous solution by silica-multiwall carbon nanotubes. Environ Sci Pollut Res Int 22:16721-16731. https://doi.org/10.1007/s11356-015-4866-z

Saleh TA (2015b) Mercury sorption by silica/carbon nanotubes and silica/activated carbon: a comparison study. J Water Supply Res Technol Aqua 64(8):892-903. https://doi.org/10.2166/ aqua. 2015.050

Saleh TA (2016) Nanocomposite of carbon nanotubes/silica nanoparticles and their use for adsorption of $\mathrm{Pb}(\mathrm{II})$ : from surface properties to sorption mechanism. Desalination Water Treatment 57(23):10730-10744. https://doi.org/10.1080/19443 994.2015 .1036784

Sheng JJ (2015) Status of polymer-flooding technology. https://wwwonepetro-org.research.library.u.tt/download/journal-paper/SPE174541-PA?id=journal-paper\%2FSPE-174541-PA

Sheng JJ (2017) Critical review of alkaline-polymer flooding. J Petrol Explor Prod Technol 7:147-153. https://doi.org/10.1007/s1320 2-016-0239-5

Sinanan B, Evans D, Budri M (2016) SPE 180853-MS: Conceptualizing an improved oil recovery master plan for Trinidad \& Tobago. SPE J. https://doi.org/10.2118/180853-MS

Taber JJ, Martin FD, Seright RS (1997) EOR screening criteria revisited part 1: introduction to screening criteria and enhanced recovery field projects. In: SPE reservoir engineering. https:// www-onepetro-org.research.library.u.tt/download/journal-paper /SPE-35385-PA?id=journal-paper\%2FSPE-

van de Hoek JE, Botermans W, Zitha PL (2001) Full blocking mechanism of polymer gels for water control. SPE 68982 In: Proceedings of society of petroleum engineers European formation damage conference, The Hague, The Netherlands

Publisher's Note Springer Nature remains neutral with regard to jurisdictional claims in published maps and institutional affiliations.

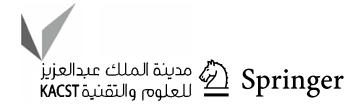

